Bayero Journal of Pure and Applied Sciences, 11(1): 88 - 92

ISSN 2006 - 6996

\title{
EVALUATION OF CORROSION BEHAVIOUR OF ALUMINUM IN DIFFERENT ENVIRONMENT
}

\author{
Musa Husaini, Bishir Usman and Muhammad Bashir Ibrahim \\ Department of Pure and Industrial Chemistry, Faculty of Physical Sciences, \\ Bayero University, P.M.B. 3011, Kano. Nigeria \\ Corresponding author: musahusaini36@gmail.com; mbibrahim.chm@buk.edu.ng
}

\begin{abstract}
The corrosion behaviour of aluminum in hydrochloric, nitric, sulfuric and phosphoric acids was investigated using weight loss method. The results shows that the corrosion rate of aluminium in $\mathrm{HCl}, \mathrm{H}_{3} \mathrm{PO}_{4}, \mathrm{H}_{2} \mathrm{SO}_{4}$ and $\mathrm{HNO}_{3}$ are $39.1200,1.5000,0.7111$ and $0.6500 \mathrm{mg} \mathrm{cm}^{-2} h^{1}$ respectively. The corrosion rate was found to increase with increase in concentration and temperature. The thermodynamic and kinetic parameters were evaluated and enthalpy $\Delta H$ was found to be positive indicating the endothermic nature of the reactions. The study further reveals that the rate of corrosion in different environment follows the following order. $\mathrm{HCl}>\mathrm{H}_{3} \mathrm{PO}_{4}>\mathrm{H}_{2} \mathrm{SO}_{4}>\mathrm{HNO}_{3}$.
\end{abstract}

Keywords: aluminum, weight loss, corrosion rate, thermodynamic and kinetic parameters

\section{INTRODUCTION}

Corrosion is the deterioration of a material, usually a metal, because of reaction with its environment (Rosliza et al., 2010). Metal interaction with environment is a process that cannot be disregarded when the issue of corrosion and its effect comes to play. The metal in the combined state tends to revert back to its most stable natural state on exposure to certain environmental conditions (Ajanaku et al., 2015). Corrosion process has affected a number of industries resulting into loss and damages of many materials and life (Barbara and Robert, 2006). The effect of corrosion on aqueous environment of sea water, salt water and rain water, can be felt when pipes corroded with toxic metals into the environment thereby causing health complications to the living system (Holsen et al., 1991). Other causes can be hazardous, which may results in loss of capital, loss of equipment and alienation of workforce, fire and explosion etc. (Holsen et al., 1991). When metals are exposed to aggressive environments such as, the use of acid solutions for pickling, chemical and electrochemical etching of metal, industrial acid cleaning, cleaning of oil refinery equipment, oil well acidizing and acid descaling, they usually lead to loss of the metal due to corrosion (Ating et al., 2010; Bishir et al., 2017). The problem of metallic corrosion has received significant concerns. It has been estimated that approximately $5 \%$ of an industrialized nations income is spent on corrosion prevention, maintenance and replacement of products lost or contaminated due to corrosion reactions (Abiola, 2002). The study of aluminum corrosion in different acidic and alkaline environments has attracted considerable attention in view of its important applications (Eduok et al., 2012). Aluminum is highly electropositive and considered as one of the most important metals due to its economic and technical importance as well as the wide range of industrial and domestic applications such as reflectors, decorative products, buildings, airspace, aircraft, architectural, packaging, construction, a wide range of household items (Hurlen et al., 1984). Aluminium is remarkable for its low density and its ability to resist corrosion because of hard, tough film of oxide it forms on the surface through the phenomenon called passivation (Abdel-Gaber et al., 2006). Acid medium such as $\mathrm{HCl}, \mathrm{HNO}_{3}, \mathrm{H}_{2} \mathrm{SO}_{4}$ and $\mathrm{H}_{3} \mathrm{PO}_{4}$ used for industrial maintenance operations often cause the structure position of aluminum to corrodes. It is in this regard that different acids used in industrial application need to be assessed and evaluate their corrosion effects in order to find the best acid that could be used in cleaning, pickling, descaling and all other industrial applications that need the use of acid. Therefore the aim of the present work is to investigate the corrosion rate of aluminum in different acidic environments using weight loss method. 
Special Conference Edition, November, 2018 MATERIAL AND METHODS

Sample Preparation

Aluminum sheets (Al 99\% purity) were obtained from Metal Focus Fabrication Technology Incubation Centre Kano State, Nigeria. Each sheet was pressed cut into $2 \times 3 \times 0.1 \mathrm{~cm}^{3}$. The coupons were polished with $240,640,800$ and 1000 grade of different emery paper respectively. The coupons were degreased in ethanol and dried in acetone, then kept in desiccator prior to use.

\section{Corrosive Media Preparation}

A stock solution of analytical grade hydrochloric acid $(36.5 \%, 1.18 \mathrm{~g} / \mathrm{L})$, nitric acid (68\%, $1.51 \mathrm{~g} / \mathrm{L})$, sulfuric acid(98\%, $1.84 \mathrm{~g} / \mathrm{L})$ and phosphoric acid (85\%, $1.68 \mathrm{~g} / \mathrm{L})$ were prepared by using double distilled water. The acid solutions of required concentrations of $0.2,0.4,0.6,0.8,1.0,1.2$ and $1.4 \mathrm{M}$ were prepared by appropriate dilutions.

\section{Weight loss Measurement}

During the weight loss experiments, aluminum coupons were weight $\left(\mathrm{w}_{1}\right)$ and suspended completely in $0.2 \mathrm{M}$ solutions of different acids in $100 \mathrm{ml}$ beaker respectively. The volume of the solution was kept at $50 \mathrm{ml}$. The coupons were retrieved after 30,60,120, 150, 180 and $210 \mathrm{~min}$, washed with distilled water, dried with acetone and reweighed $\left(w_{2}\right)$. The immersion time with relatively higher weight loss was adopted as optimum immersion time. From the weight loss data, corrosion rate in $\mathrm{mgcm}^{-2} \mathrm{~h}^{-1}$ was calculated using equations 1 and 2 (Khandelwal et al., 2011)

$\Delta \mathrm{W}=\mathrm{W}_{1}-\mathrm{W}_{2}$

Corrosion rate $\left(\mathrm{mg} \mathrm{cm}^{-2} \mathrm{~h}^{-1}\right)=\frac{\text { Weight loss }}{\text { Area } \times \text { Time }}$

Where $w_{1}$ and $w_{2}$ are the weight of coupons before and after immersion in the corrodent medium respectively.

\section{Effect of Concentration}

To study the effect of corrodent concentration the prepared weighted aluminium coupon was immersed in $0.2,0.4,0.6,0.8,1.0,1.2$ and $1.4 \mathrm{M}$ corrodent maintained at $308 \mathrm{~K}$ for $3 \mathrm{hrs}$ immersion time. The final weight was taken and the weight loss was calculated. The concentration with relatively higher weight loss was considered as the optimum concentration.

\section{Effect of Temperature}

To study the effect of temperature, the prepared weighted aluminium coupon was immersed in $1.4 \mathrm{M}$ corrodent concentration at $308,313,318,323$ and $328 \mathrm{~K}$ for $3 \mathrm{hrs}$. The final weight was taken, the weight loss and corrosion rate was calculated.

\section{RESULTS AND DISCUSSION}

\section{The Effect of Immersion Time}

The result obtained from Table 1 shows that the weight loss of aluminium in $\mathrm{HCl}, \mathrm{HNO}_{3}$, $\mathrm{H}_{2} \mathrm{SO}_{4}$ and $\mathrm{H}_{3} \mathrm{PO}_{4}$ increased with increase in immersion time. At least immersion time of 30 min the weight loss of aluminum in $\mathrm{HCl}$, $\mathrm{HNO}_{3}, \mathrm{H}_{2} \mathrm{SO}_{4}$ and $\mathrm{H}_{3} \mathrm{PO}_{4}$ are $0.0018,0.0011$, 0.0014 and $0.0016 \mathrm{~g}$ while at highest immersion time of $3 \mathrm{hrs}$ the weight loss increased to $0.0199,0.0063,0.0068$ and $0.0119 \mathrm{~g}$. Increase of the rate of weight loss of the metal in the given acids indicates the instability of protective film for the longer contact period. Increased in weight loss with immersion time is due to the interaction that occur between the acid and the metal surface in solution, which tend to destroy the metal surface gradually with time thereby increasing the weight loss of the metal. Weight loss in constant concentration of the corrodent increased with increase in immersion time. Similar work was done by Patil and Sharma (2011) during the study of corrosion kinetics of iron in acid and base medium and reported that the weight loss increases with increase in immersion time and the result of the weight loss in acid medium was 0.0152 , $0.0308,0.0469$ and $0.0626 \mathrm{~g}$ at 2, 4, 6 and $8 \mathrm{hrs}$.

Table 1: Weight loss of Aluminum Corrosion at Different Immersion Time

\begin{tabular}{ccccc}
\hline Time (min) & $\mathrm{HCl}$ & $\mathrm{HNO}_{3}$ & $\mathrm{H}_{2} \mathrm{SO}_{4}$ & $\mathrm{H}_{3} \mathrm{PO}_{4}$ \\
\hline 30 & 0.0018 & 0.0011 & 0.0014 & 0.0016 \\
60 & 0.0040 & 0.0019 & 0.0020 & 0.0038 \\
90 & 0.0063 & 0.0023 & 0.0029 & 0.0053 \\
120 & 0.0098 & 0.0043 & 0.0046 & 0.0074 \\
150 & 0.0140 & 0.0056 & 0.0057 & 0.0098 \\
180 & 0.0199 & 0.0063 & 0.0068 & 0.0119 \\
\hline
\end{tabular}

The Effect of Concentration

The result of changes in concentration (Table 2) shows that as the concentration of the acids increase the weight loss and corrosion rate increases, this is due to the fact that the rate of chemical reaction increases as the concentration of active species increases. 
Special Conference Edition, November, 2018

At least acid concentration of $0.2 \mathrm{M}$ the weight loss and corrosion rate of aluminium in $\mathrm{HCl}$, $\mathrm{HNO}_{3}, \mathrm{H}_{2} \mathrm{SO}_{4}$ and $\mathrm{H}_{3} \mathrm{PO}_{4}$ are $(0.0205,0.0062$, 0.0069 and $0.0120 \mathrm{~g})$ and $(1.1388,0.3444$, 0.3833 and $0.6667 \mathrm{mg} \mathrm{cm}^{-2} \mathrm{~h}^{-1}$ ). While at highest acid concentration of $1.4 \mathrm{M}$ the weight loss and corrosion rate increased to $(0.3515$, $0.0117,0.0128$ and $0.0270 \mathrm{~g})$ and (19.5277, $0.6500,0.7111$ and $1.5000 \mathrm{mg} \mathrm{cm}^{-2} \mathrm{~h}^{-1}$ ). The dissolution rate of aluminium depend on the concentration of the corrosive media, this could be attributed to increase in concentration of the acid anions in the more concentrated solution, which readily react with aluminum ion present in the solution. Similar observation was reported by Rathod and Vashi (2016) who investigated the effect of ammonium dichromate on the corrosion of aluminum in phosphoric acid and the result showed that the corrosion rate increased with increase in the concentration of the acid and the result of the corrosion rate was found to be $389.7,454.0,486.2$ and $525.6 \mathrm{mg} / \mathrm{dm}^{2}$ in 1.0 , $1.25,1.50$ and $1.75 \mathrm{M} \mathrm{H}_{3} \mathrm{PO}_{4}$

Table 2: Corrosion rate of Aluminum at Different Acids Concentration

\begin{tabular}{|c|c|c|c|c|c|c|c|c|}
\hline \multirow{2}{*}{ 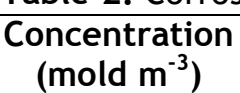 } & \multicolumn{4}{|c|}{ Weight Loss (g) } & \multicolumn{4}{|c|}{ Corrosion Rate $\left(\mathrm{mg} \mathrm{cm}^{-2} \mathrm{~h}^{-1}\right)$} \\
\hline & $\mathrm{HCl}$ & $\mathrm{HNO}_{3}$ & $\mathrm{H}_{2} \mathrm{SO}_{4}$ & $\mathrm{H}_{3} \mathrm{PO}_{4}$ & $\mathrm{HCl}$ & $\mathrm{HNO}_{3}$ & $\mathrm{H}_{2} \mathrm{SO}_{4}$ & $\mathrm{H}_{3} \mathrm{PO}_{4}$ \\
\hline 0.2 & 0.0205 & 0.0062 & 0.0069 & 0.0120 & 1.1388 & 0.3444 & 0.3833 & 0.6667 \\
\hline 0.4 & 0.0340 & 0.0075 & 0.0078 & 0.0160 & 1.8888 & 0.4167 & 0.4333 & 0.8889 \\
\hline 0.6 & 0.0690 & 0.0082 & 0.0085 & 0.0 & 3.8333 & 0.4556 & 0.4722 & 0.8556 \\
\hline 0.8 & 0.1 & 0 & & 0.0 & 7.6666 & & & 1.2111 \\
\hline 1.0 & 0.21 & 0.0098 & 0.0104 & 0.0 & 11.9500 & 0.5444 & 0.5 & 1.3000 \\
\hline 1.2 & 0.2760 & 0.0102 & 0.0115 & 0.0250 & 15.3333 & 0.5667 & 0.6389 & 1.3889 \\
\hline 1.4 & 0.3515 & 0.0117 & 0.0128 & 0.0270 & 19.5277 & 0.6500 & 0.7111 & 1.5000 \\
\hline
\end{tabular}

The Effect of Temperature

The results in Table 3 shows that the rate of corrosion increases with increase in temperature. High temperature produce more severe corrosion condition. At the lowest temperature $(303 \mathrm{~K})$ used, the weight loss and corrosion rate of aluminium in $\mathrm{HCl}, \mathrm{HNO}_{3}, \mathrm{H}_{2} \mathrm{SO}_{4}$ and $\mathrm{H}_{3} \mathrm{PO}_{4}$ are $(0.3102,0.0090,0.0101$ and $0.0201 \mathrm{~g})$ and $(17.2333,0.5000,0.5611$ and $\left.1.1167 \mathrm{mg} \mathrm{cm}^{-2} \mathrm{~h}^{-1}\right)$. With increasing the temperature to $328 \mathrm{~K}$ the weight loss and corrosion rate increased to $(0.5811,0.0270$, 0.0299 and $0.0602 \mathrm{~g})$ and $(32.2833,1.5000$, 1.6611 and $3.3444 \mathrm{mg} \mathrm{cm}^{-2} \mathrm{~h}^{-1}$ ). Increase in temperature usually increases the solubility of the protective films through increase in the average kinetic energy of the constituent particles. As the average kinetic energy increases the particles move faster and collide more frequently which result in the increase of the reaction rate as reported by Olasehinde et al. (2013) and Ahmad et al. (2014). Similar observation was reported by Rathod and Vashi (2016) who investigated the effect of ammonium dichromate on the corrosion of aluminum in phosphoric acid and the result showed that the corrosion rate increased with increasing temperature and the corrosion rate was found to be $92.95,175.18$ and 425.45 $\mathrm{mg} / \mathrm{dm}^{2}$ at 313,323 and $333 \mathrm{~K}$.

Table 3: Corrosion rate of Aluminum in Acid at Different Temperature

\begin{tabular}{ccccccccc}
\hline Temperature (K) & \multicolumn{4}{c}{ Weight loss(g) } & \multicolumn{4}{c}{ Corrosion rate $\left.\mathbf{m g ~ c m}^{-2} \mathbf{h}^{-1}\right)$} \\
& $\mathrm{HCl}$ & $\mathrm{HNO}_{3}$ & $\mathrm{H}_{2} \mathrm{SO}_{4}$ & $\mathrm{H}_{3} \mathrm{PO}_{4}$ & $\mathrm{HCl}$ & $\mathrm{HNO}_{3}$ & $\mathrm{H}_{2} \mathrm{SO}_{4}$ & $\mathrm{H}_{3} \mathrm{PO}_{4}$ \\
\hline 303 & 0.3102 & 0.0090 & 0.0101 & 0.0201 & 17.2333 & 0.5000 & 0.5611 & 1.1167 \\
308 & 0.3515 & 0.0117 & 0.0128 & 0.0270 & 19.5277 & 0.6500 & 0.7111 & 1.5000 \\
313 & 0.3951 & 0.0134 & 0.0170 & 0.0330 & 21.9500 & 0.7444 & 0.9444 & 1.8333 \\
318 & 0.4521 & 0.0181 & 0.0200 & 0.0403 & 25.1166 & 1.0055 & 1.1111 & 2.2388 \\
323 & 0.5002 & 0.0221 & 0.0254 & 0.0493 & 27.7888 & 1.2277 & 1.4111 & 2.7388 \\
328 & 0.5811 & 0.0270 & 0.0299 & 0.0602 & 32.2833 & 1.5000 & 1.6611 & 3.3444 \\
\hline
\end{tabular}

In all the three given parameters above $\mathrm{HCl}$, shows the high reactivity over $\mathrm{HNO}_{3}, \mathrm{H}_{2} \mathrm{SO}_{4}$ and $\mathrm{H}_{3} \mathrm{PO}_{4}$. In the effect of immersion time the weight loss at $3 \mathrm{hrs}$ of $\mathrm{HCl}, \mathrm{HNO}_{3}, \mathrm{H}_{2} \mathrm{SO}_{4}$ and $\mathrm{H}_{3} \mathrm{PO}_{4}$ are $0.0338,0.0063,0.0068$ and $0.0119 \mathrm{~g}$. In the effect of concentration the corrosion rate at $1.4 \mathrm{M}$ solution of $\mathrm{HCl}, \mathrm{HNO}_{3}, \mathrm{H}_{2} \mathrm{SO}_{4}$ and
$\mathrm{H}_{3} \mathrm{PO}_{4}$ are $39.1200,0.6500,0.7111$ and 1.5000 $\mathrm{mg} \mathrm{cm} \mathrm{cm}^{-2} \mathrm{~h}^{-1}$. In the effect of temperature the corrosion rate of $\mathrm{HCl}, \mathrm{HNO}_{3}, \mathrm{H}_{2} \mathrm{SO}_{4}$ and $\mathrm{H}_{3} \mathrm{PO}_{4}$ at $328 \mathrm{~K}$ are $42.43,1.2278,1.7222$ and $7.2278(\mathrm{mg}$ $\left.\mathrm{cm}^{-2} \mathrm{~h}^{-1}\right)$. The reactivity of the acids follow the variation pattern $\mathrm{HCl}>\mathrm{H}_{3} \mathrm{PO}_{4}>\mathrm{H}_{2} \mathrm{SO}_{4}>\mathrm{HNO}_{3}$. 
Special Conference Edition, November, 2018

The highest reactivity of $\mathrm{HCl}$ is due do the fact that $\mathrm{HCl}$ is a typical reducing acid across its entire concentration range. Its strongly acidic character and the harmful effect of the chloride ion combine to make it a very severe corrosive. The $\mathrm{HNO}_{3}$ has the least reactivity in the variation pattern because it's strong oxidizing acid that form a thin layer of aluminum oxide to coat the surface of aluminum through the process called passivation (Ahmed et al., 2009; Singh et al., 1981). While Pure $\mathrm{H}_{3} \mathrm{PO}_{4}$ has no effective oxidizing power and is classified as a nonoxidizing acid, so it shows higher reactivity with aluminum than $\mathrm{H}_{2} \mathrm{SO}_{4}$ because concentrated $\mathrm{H}_{2} \mathrm{SO}_{4}$ (above $87 \%$ by weight) at room temperature is oxidizing in nature (Laque and Copson 1963).

Thermodynamic and Kinetic Parameters

The apparent activation energies (Ea) were calculated from Arrhenius (equation 3) (Shivakumar and Mohana 2013; Hegazy et a., 2012) and the results are presented in Table 4. $\ln \left(C_{R}\right)=B-\frac{E_{a}}{R T}$

Where $B$ is a constant, $R$ is the universal gas constant, and $T$ is the absolute temperature. The plot of $\ln \left(C_{R}\right)$ Vs reciprocal of absolute temperature $(1 / T)$ gave a straight line with slope $=-E a / R$, from which the activation energy values for the corrosion process was calculated.

The Thermodynamic parameters enthalpy and entropy of activation were calculated using the transition state equation (Putilova et al., 1960; Hegazy et al., 2013).
$\left(\frac{C_{R}}{T}\right)=\ln \left(\frac{R}{N h}\right)+\left(\frac{\Delta S_{a}}{R}\right)-\left(\frac{\Delta H_{a}}{R T}\right)$ In

Where $h$ is Plank's constant and $N$ is Avogadro's number. A plot of $\ln \left(C_{R} / T\right)$ vs $1 / T$ gave a straight show with slope $=-\Delta H a / R$ and intercept $=\ln (R / N h)+\Delta S a / R$. The calculated values of enthalpy and entropy from the plots were presented in Table 4.

Table 4: Activation Parameters for the Corrosion of Aluminum in Different Acid solutions

\begin{tabular}{cccc} 
Acids $(M)$ & Ea $\left(\mathrm{kJ} \mathrm{mol}^{-1}\right)$ & $\Delta \mathrm{H}\left(\mathrm{kJ} \mathrm{mol}^{-1}\right)$ & $\Delta \mathrm{S}\left(\mathrm{J} \mathrm{mol}^{-1} \mathrm{~K}^{-1}\right)$ \\
\hline $\mathrm{HCl}$ & 20.44 & 17.82 & -175.02 \\
$\mathrm{H}_{3} \mathrm{PO}_{4}$ & 35.40 & 32.78 & -193.06 \\
$\mathrm{H}_{2} \mathrm{SO}_{4}$ & 36.14 & 33.52 & -196.50 \\
$\mathrm{HNO}_{3}$ & 36.36 & 33.80 & -196.69 \\
\hline
\end{tabular}

From Table 4, the values of energy of activation for the corrosion of aluminium in $\mathrm{HCl}, \mathrm{HNO}_{3}, \mathrm{H}_{2} \mathrm{SO}_{4}$ and $\mathrm{H}_{3} \mathrm{PO}_{4}$ are 20.44, 35.40, 36.14 and $36.36 \mathrm{~kJ} \mathrm{~mol}^{-1}$. $\mathrm{HCl}$ has the least value of $\mathrm{Ea}$ while $\mathrm{HNO}_{3}$ has the highest, this is considered as good evidence supporting the highest and lowest corrosion rates recorded in the $\mathrm{HCl}$ and $\mathrm{HNO}_{3}$ system. The Ea values of all the acid are greater than $20 \mathrm{~kJ} \mathrm{~mol}^{-1}$ this suggested that the whole process is controlled by surface reaction as reported by Bouklah et al. (2005). The values of the entropy change $(\Delta \mathrm{S})$ for the corrosion of aluminium in $\mathrm{HCl}$, $\mathrm{HNO}_{3}, \mathrm{H}_{2} \mathrm{SO}_{4}$ and $\mathrm{H}_{3} \mathrm{PO}_{4}$ are -175.02, -193.06, 196.50 and $-196.69 \mathrm{Jmol}^{-1} \mathrm{~K}^{-1}$. The $\Delta \mathrm{S}$ values are large and negative, this implies that the activated complex in the rate determining step represents association rather than dissociation indicating that a decrease in disorder takes place. The values of enthalpy change $(\Delta \mathrm{H})$ for the corrosion of aluminium in $\mathrm{HCl}, \mathrm{HNO}_{3}, \mathrm{H}_{2} \mathrm{SO}_{4}$

\section{REFERENCES}

Abdel-Gaber A., Abd-El-Nabey B., Sidahmed I., A. M. El-Zayady A. and Saadawy M. (2006); Kinetics and Thermodynamics of and $\mathrm{H}_{3} \mathrm{PO}_{4}$ are $17.82,32.78,33.52$ and $33.80 \mathrm{~kJ}$ $\mathrm{mol}^{-1}$. The positive signs of $\Delta \mathrm{H}$ reflect that transition state (the activated complex) is endothermic process. Similar observation was reported by Ahmed et al. (2011) who studied the galvanic corrosion of aluminum Alloy (Al2024) in $1.0 \mathrm{M}$ nitric acid and the result obtained for activation energy (Ea), enthalpy change $(\Delta \mathrm{H})$ and entropy chasnge $(\Delta \mathrm{S})$ were $50.54 \mathrm{~kJ} \mathrm{~mol}^{-1}, 47.91 \mathrm{~kJ} \mathrm{~mol}^{-1}$ and $-85.63 \mathrm{~J} \mathrm{~mol}^{-1}$ $\mathrm{K}^{-1}$

\section{CONCLUSION}

Based on the results of weight loss measurements conclusions are drawn in this study; Weight loss increases with increase in immersion time in all acids environment. The corrosion rate increases with increase in the concentration and temperature. Corrosion rate of aluminum in different environment follows the order $\mathrm{HCl}>\mathrm{H}_{3} \mathrm{PO}_{4}>\mathrm{H}_{2} \mathrm{SO}_{4}>\mathrm{HNO}_{3}$.

Aluminium Dissolution in $1.0 \mathrm{M}$ Sulphuric Acid Containing Chloride lons. Materials, Chemistry and Physics 98: 291-297. 
Abiola O. (2002); "Kinetic studies of corrosion inhibition of mild steel and aluminium by (4Amino-2-5-Pyrimidinyl Methylthio) Acetic acid, 3-[4-amino-2-methyl-5-pyrimidyl methyl]-5-[2hydroxylethyl]-4-methyl Thiazolium chloride hydrochloride and Thioglycolic acid in hydrochloric acid" published Ph.D Thesis, Department of Pure and Industrial Chemistry, University of Port-Harcourt, Nigeria.

Ahmad M., Al-haj, A., Nabeel, A., Nuhu, D. and Rihan O. (2014). Thermodynamics and Kinetics of Inhibition of Aluminium in Hydrochloric Acid by Date Palm Leaf Extract. Journal of Applied Science Environment. 18(3): 543 - 551.

Ahmed, Y. M., Abubakar, M. and Abdul-Amir H. K. (2011). Galvanic Corrosion of Aluminum Alloy (Al2024) and Copper in 1.0 M Nitric Acid. Int. J. Electrochem. Sci., 6: 5052 - 5065.

Ating E., Umoren S., Udousoro L., Ebenso E. and Udoh A. (2010); "Leaves extract of Ananas Sativum as green corrosion inhibitor for aluminium in hydrochloric acid solutions" Green Chemistry Letters and Reviews. 3(2): 61-68.

Ajanaku K. 0.1, Aladesuyi 0.1, Ajanaku C.0.1, Adedapo E.A.1, Akinsiku A.A. and Sodiya F.E. (2015); Adsorption properties of Azadirachta indicia extract on corrosion of Aluminium in $1.85 \mathrm{M}$ Hydrochloric acid. Journal of International Association of Advanced Technology and Science. 16: 261-173.

Barbara S. and Robert K. (2006). What is corrosion? The electrochemical society interface, 6: 2426.

Bishir U., Hasmerya M., Hassan H., Abdallah and Mazdalan A (2017); Inhibition of performance of mild steel corrosion in acidic media using 2thiophhene acetyle chloride. Bayero journal of pure and applied science. 10(1): 590 - 595.

Bouklah M., Hammouti B., and Benkaddour M. (2005); Thiophene derivatives as effective inhibitors for the corrosion of steel in $0.5 \mathrm{~m}$ $\mathrm{H}_{2} \mathrm{SO}_{4}$. Journal of Applied Electrochemical Science, 35: 1095-1101.

Eduok, U. M., Umoren S. A., Udoh A. (2012); Synergistic inhibition effects between leaves and stem extracts of Sida acuta and lodide ion for mild steel corrosion in $1 \mathrm{M} \mathrm{H}_{2} \mathrm{SO}_{4}$ solutions, Arabian Journal of Chemistry. 5: 325-337.

Hegazy M., Hasan A., Emara M., Bakr, M. and Youssef A. (2012). Evaluating four synthesized Schiff bases as corrosion inhibitors on the carbon steel in $1 \mathrm{M}$ hydrochloric acid. Journal of Corrosion Science. 65: 67-76.

Hegazy M., Badawi, A., Abd El Rehim S. and Kamel W. (2013); Corrosion inhibition of carbon steel using novel $\mathrm{N}$-(2-(2-mercaptoacetoxy) ethyl)-N, N-dimethyl dodecan-1-aminium bromide during acid pickling. Journal of Corrosion Science. 69: 110-122.

Holsen T. M., Park, J. K., Bontoux L., Jenkins D., Selleck, R.E., (1991) The Effect of Soils on the Permeation of Plastic Pipes by Organic Chemicals, Journal AWWA, 83(11): 85-91.

Hurlen T., Lian H., Odegard O.S. and Valand T. (1984); Corrosion and passive behaviour of aluminum in weakly acid solution. Electrochemical Acta; 29: 579- 85.

Jonathan, M., Nwaedozie, Efiok, J., Adeyemi, A. and Olufemi, O. (2015). Inhibition and Kinetic Studies of Gmelina aborea Fruit Extract on Corrosion of Armour Steel Plate in Hydrochloric Acid. International Journal of Scientific and Engineering Research. 6(5): 785 - 896.

Khandelwal, R.; Arora, S.K. and Mathur S.P. (2011). "Study of Plant Cordia Dichotoma as Green Corrosion Inhibitor for Mild Steel in Different Acid Media", E-Journal of Chemistry, 3: 12001205.

Laque, F. L. and Copson, H. R. (1963). Corrosion Resistance of Metals and Alloys, $2^{\text {nd }}$ Edition. Reinhold Publishing Corporation. New York:

Olasehinde, E.F., Olusegu, S.J., Adesina, A.S., Omogbehin, S.A. and Yahayah, M. (2013). Inhibitory Action of Nicotiana Tabacum Extracts on the Corrosion of Mild Steel in $\mathrm{HCl}$. Journal of Natural Science. 11(1): 83 - 90.

Patil, J.B. and Sharma, A.R. (2011). Study on the Corrosion Kinetics of Iron in Acid and Base Medium. E - Journal of Chemistry. 8(51): 5358 - 5362.

Putilova I., Balezin S. and Barannik V. (1960); Metallic Corrosion Inhibitors, Pergamon Press, New York, 31.

Rathod K and Vashi R (2016); Inhibition effect of ammonium dichromate on the corrosion of aluminum in phosphoric acid. International Journal of Chemical Studies. 4(1): 37- 42.

Rosliza R, Wan Nik WB, Izman S and Prawoto $Y$ (2010). Anti - corrosive Properties of Natural Honey on Al-Mg-Si Alloy in Seawater. Curr. Appl. Phys., 10(3): 923 - 929.

Shivakumar S. and Mohana K. (2013). Inhibitive Performance of Cinnamomum Zeylanicum Extracts on the corrosion of Mild- steel in hydrochloric and Sulphuric Acid. Journal of Material and Environmental. Science. 4(3): $448-459$.

Singh, D.D.N., Singh, M.M., Chaudhary, R.S. and Agarwal, C.V. (1981). Inhibition and polarization studies of some substituted urea compounds for corrosion of aluminum in nitric acid, Electrochim. Acta. 26: 1051-1056.

Soltani N., Salavati H., Rasouli N., Paziresh M. and Moghadasi A. (2016); Adsorption and Corrosion Inhibition Effect of Schiff Base Ligands on Low Carbon Steel Corrosion in Hydrochloric Acid Solution. Chemical Engineering Communications, 203: 840-854.

Vashi R and Prajapati N (2017); Corrosion Inhibition of Aluminum in Hydrochloric Acid Using Bacopa monnieri Leaves Extract as Green Inhibitor. International Journal of Chemical and Technical Research. 10(15): 221-231 